\title{
Landslides, floods and sinkholes in a karst environment: the 1-6 September 2014 Gargano event, southern Italy
}

\author{
Maria Elena Martinotti ${ }^{1}$, Luca Pisano ${ }^{2,6}$, Ivan Marchesini ${ }^{1}$, Mauro Rossi ${ }^{1}$, Silvia Peruccacci ${ }^{1}$, \\ Maria Teresa Brunetti ${ }^{1}$, Massimo Melillo ${ }^{1}$, Giuseppe Amoruso ${ }^{3}$, Pierluigi Loiacono ${ }^{3}$, Carmela Vennari ${ }^{2,4}$, \\ Giovanna Vessia $^{2,5}$, Maria Trabace ${ }^{3}$, Mario Parise ${ }^{2, \mathrm{a}}$, and Fausto Guzzetti ${ }^{1}$ \\ ${ }^{1}$ Consiglio Nazionale delle Ricerche, Istituto di Ricerca per la Protezione Idrogeologica, \\ via Madonna Alta 126, 06128 Perugia, Italy \\ ${ }^{2}$ Consiglio Nazionale delle Ricerche, Istituto di Ricerca per la Protezione Idrogeologica, \\ via Amendola 122, 70126 Bari, Italy \\ ${ }^{3}$ Regione Puglia, Servizio di Protezione Civile, Via delle Magnolie 6/8, 70126 Modugno (Bari), Italy \\ ${ }^{4}$ University of Naples "Federico II", Naples, Italy \\ ${ }^{5}$ University of Chieti-Pescara "Gabriele D'Annunzio", Chieti, Italy \\ ${ }^{6}$ University of Molise, Department of Biosciences and Territory, Contrada Fonte Lappone, Pesche (IS), Italy \\ apresent address: University "Aldo Moro", Department of Earth and Environmental Sciences, Via Orabona 7, \\ 70126 Bari, Italy
}

Correspondence to: Maria Elena Martinotti (maria.elena.martinotti@irpi.cnr.it)

Received: 23 September 2016 - Discussion started: 31 October 2016

Revised: 8 February 2017 - Accepted: 24 February 2017 - Published: 22 March 2017

\begin{abstract}
In karst environments, heavy rainfall is known to cause multiple geohydrological hazards, including inundations, flash floods, landslides and sinkholes. We studied a period of intense rainfall from 1 to 6 September 2014 in the Gargano Promontory, a karst area in Puglia, southern Italy. In the period, a sequence of torrential rainfall events caused severe damage and claimed two fatalities. The amount and accuracy of the geographical and temporal information varied for the different hazards. The temporal information was most accurate for the inundation caused by a major river, less accurate for flash floods caused by minor torrents and even less accurate for landslides. For sinkholes, only generic information on the period of occurrence of the failures was available. Our analysis revealed that in the promontory, rainfalldriven hazards occurred in response to extreme meteorological conditions and that the karst landscape responded to the torrential rainfall with a threshold behaviour. We exploited the rainfall and the landslide information to design the new ensemble-non-exceedance probability (E-NEP) algorithm for the quantitative evaluation of the possible occurrence of rainfall-induced landslides and of related geohydrological hazards. The ensemble of the metrics produced
\end{abstract}

by the E-NEP algorithm provided better diagnostics than the single metrics often used for landslide forecasting, including rainfall duration, cumulated rainfall and rainfall intensity. We expect that the E-NEP algorithm will be useful for landslide early warning in karst areas and in other similar environments. We acknowledge that further tests are needed to evaluate the algorithm in different meteorological, geological and physiographical settings.

\section{Introduction}

Torrential rainfall is known to cause inundations, flash floods and different types of landslides, including debris flows, soil slides and rockfalls. Less known is that intense rainfall can cause sinkholes, a subtle hazard in many karst environments (Parise and Gunn, 2007; De Waele et al., 2011; Gutierrez et al., 2014; Parise et al., 2015). Here, we describe a series of rainfall events and their ground effects in the period from 1 to 6 September 2014 in the Gargano Promontory, a karst environment and a popular tourist area in the Puglia (Apulia) region, southern Italy. In a 6-day period, a sequence of 
four heavy rainfall events, separated by periods with little or no rainfall, caused multiple geohydrological hazards in the promontory, including landslides, flash floods, widespread inundation and sinkholes. The death toll amounted to two fatalities, and a number of people were forced to leave their homes or businesses. Urban areas, tourist resorts, roads and rails were inundated and damaged, causing severe economic consequences. We have investigated the spatial-temporal relationships between the rainfall trigger and the geohydrological hazards, and we have designed and tested an algorithm for improved early landslide warning.

The paper is organised as follows. After a brief description of the study area (Sect. 2), in Sect. 3 we present the main meteorological and rainfall characteristic of the heavy rainfall period that has resulted in landslides, flash floods, inundations and sinkholes in the Gargano Promontory, and we investigate the spatial-temporal relationships between the intense rainfall and its ground effects. Next, in Sect. 4 we present a new method to forecast the possible occurrence of rainfall-induced landslides - and possibly the other associated geohydrological hazards - based on the continuous monitoring of local rainfall conditions. This is followed, in Sect. 5, by a discussion of the results obtained, including general considerations on the effects of intense rainfall in karst environments and their possible predictability using the new rainfall-based forecasting method. We conclude (Sect. 6) summarising the lessons learnt.

\section{Study area}

The study area covers approximately $1600 \mathrm{~km}^{2}$ and encompasses the Gargano Promontory that extends for a few tens of kilometres into the Adriatic Sea, in the NE part of the Puglia region, southern Italy (Fig. 1). The Lesina and Varano coastal lakes separate the northern side of the promontory from the sea. Elevation in the area ranges from sea level to $1056 \mathrm{~m}$ a.s.l. with a mean value of about $400 \mathrm{~m}$, and morphology is controlled by E-W- and NW-SE-trending faults (Funiciello et al., 1988; Brankman and Aydin, 2004). Due to the presence of a well-developed karst environment, surface hydrography is limited to a few short ephemeral drainages along the slopes that bound the elevated central plateau, and to the Candelaro River and minor drainages in the alluvial and coastal plains surrounding the promontory. In the area, sedimentary rocks crop out, chiefly carbonate platform limestone, limited marl and residual "terra rossa" deposits (Bosellini et al., 1999). Soils, where present, are chromic Cambisols and Luvisols. Yearly cumulated rainfall ranges between 400 and $1200 \mathrm{~mm}$, and mean annual air temperature varies from 10 to $17^{\circ} \mathrm{C}$. The climate is Mediterranean to Mediterranean suboceanic. July and August are dry, and most of the precipitation falls as rainfall from September to November (Polemio and Lonigro, 2011). The promontory hosts the Gargano National Park and a number of towns and (a)

(b)
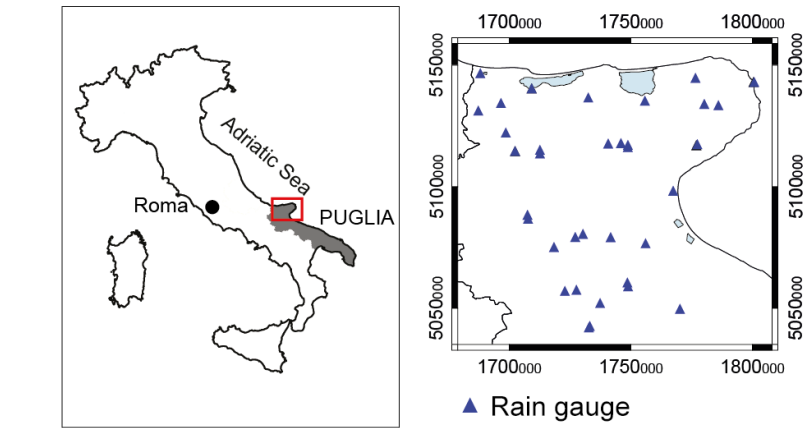

(c)

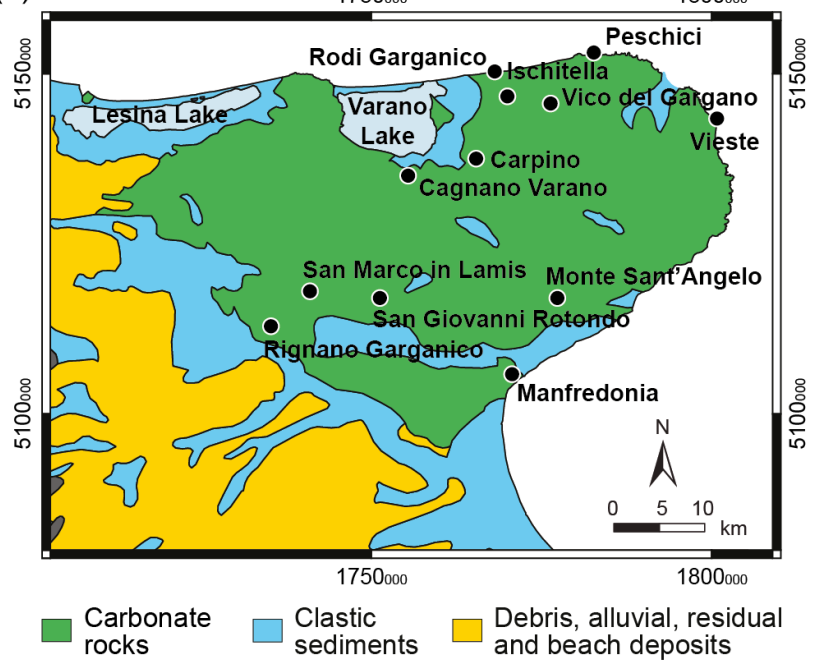

Figure 1. Panel (a) shows the location of the study area (red rectangle) in Italy. Grey area is the Puglia (Apulia) region. Panel (b) shows the location of 39 rain gauges in the study area and the neighbouring area. Panel (c) shows the main rock types (colours) and place names in the study area. WGS84/Pseudo Mercator (EPSG: 3857).

villages that collectively represent an important touristic area and a significant economic resource.

Although not particularly frequent or abundant compared to other areas in southern Italy, different geohydrological hazards have been reported in the Gargano Promontory. In recent historical times, destructive events occurred on 15 July 1972 (Bissanti, 1972) and 29 July 1976, when the city of Manfredonia, to the south of the promontory (Fig. 1), suffered inundations, and on 10-12 September 1982, when the town of San Marco in Lamis was hit by torrential rain. Landslides were reported in 1931, 1935, 1950, 1952, 1962, 1963, 1972, 1996 and 1997 and floods in 1996, 1997, 1998, 2002, 2007 and 2011. The main landslide types are rockfalls, topples and small disrupted rock slides that originate primarily from steep rock slopes. Flash floods and coastal floods occur in response to intense rainfall, but are not very frequent in the historical record. The karst environment favours the formation of sinkholes, i.e. karst forms also known as "dolines" (Ford and Williams, 2007), with a local density of up to 100 

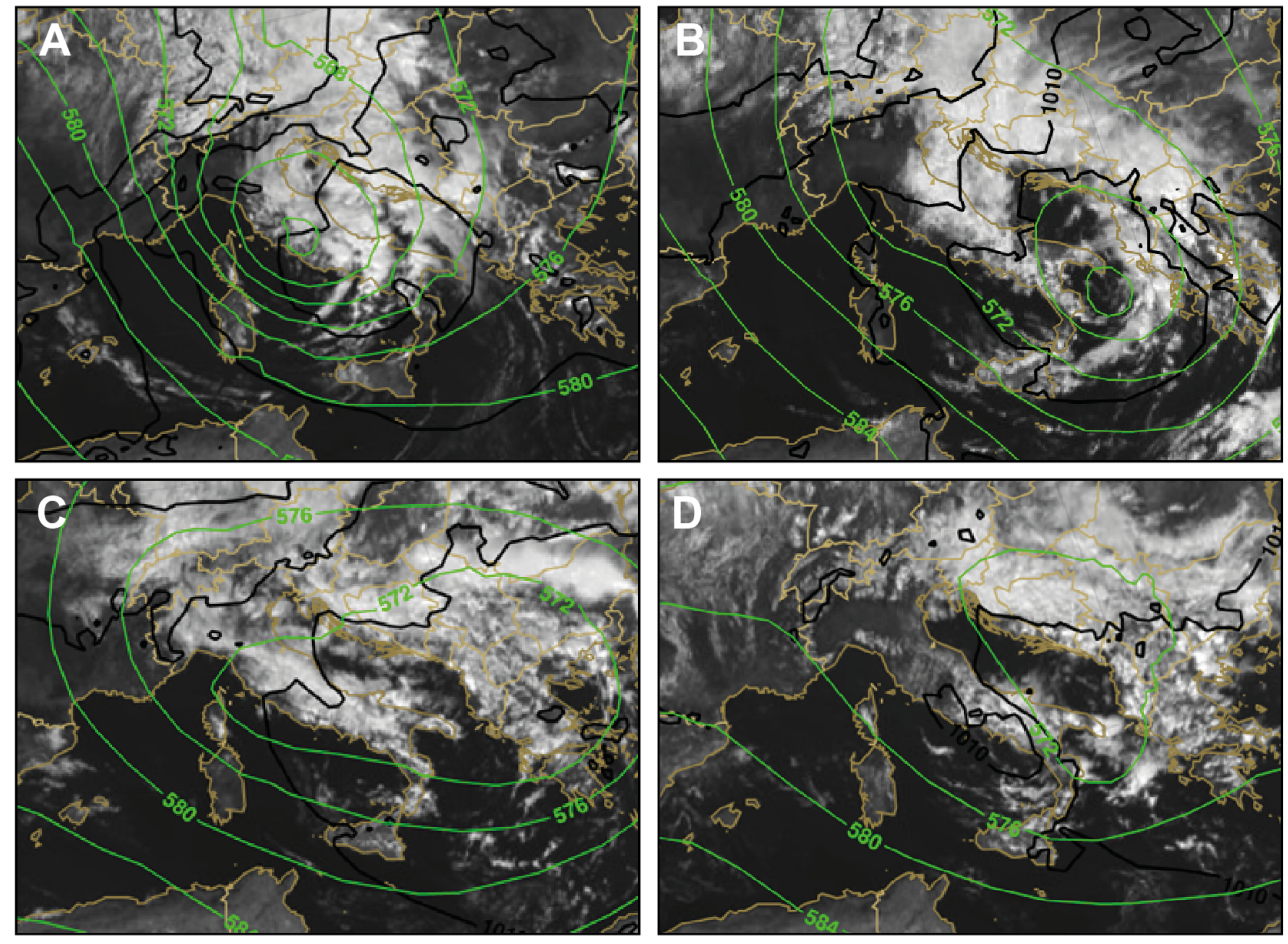

Figure 2. Meteorological setting for the period 1-6 September 2014 over central and southern Italy. Images show Meteosat Second Generation (MSG) - visible (VIS) 0.6 $\mu \mathrm{m}$ for (a) 1 September 2014, 12:00 UTC, (b) 2 September 2014, 12:00 UTC, (c) 3 September 2014, 12:00 UTC, (d) 6 September 2014, 12:00 UTC. Green lines show geopotential height of $500 \mathrm{hPa}$ pressure level. Black lines show mean sea level pressure. Light brown lines show geographical boundaries. Source: http://www.eumetrain.org.

dolines per square kilometre (Castiglioni and Sauro, 2000; Simone and Fiore, 2014). Sinkhole features in the promontory range in size from small to very small, extending a few tens of square metres, to large and deep features including the "Dolina Pozzatina" with a depth of $100 \mathrm{~m}$ and a perimeter of about $1850 \mathrm{~m}$, and to large polje, including the Sant'Egedio polje, near San Giovanni Rotondo (Fig. 1).

\section{Description of the events}

\subsection{Meteorological settings}

The meteorological event that brought torrential rainfall in the Gargano area began on 1 September 2014, when a perturbed nucleus originating from northern Europe moved to lower latitudes and impacted the Italian peninsula, starting from the northern and eastern sectors. In the early afternoon of 1 September, the central and southern parts of the Italian peninsula were first affected (Fig. 2a). Between 2 and 3 September, the low-pressure vortex moved towards the Ionian Sea and then to the Balkans and the Hellenic peninsula. The meteorological situation determined an inflow of perturbed masses of air over most of the Adriatic regions (Fig. 2b, c). The anticlockwise circulation affected most of central and southern Italy and persisted until 6 September.
Residual perturbed meteorological conditions remained over the southern Italian regions; in particular those facing the Ionian Sea, with isolated minor precipitations until the late morning of 7 September (Fig. 2d).

\subsection{Rainfall events}

The perturbed meteorological conditions over Italy resulted in torrential precipitation in the Gargano Promontory, with cumulated rainfall exceeding $500 \mathrm{~mm}$ in the 6-day period 1 6 September (Fig. 3). To study the intense rainfall period, we used hourly rainfall records available for 39 rain gauges pertaining to the national network of rain gauges operated in the area by the Italian National Department of Civil Protection and the Puglia Regional Government. Inspection of the rainfall records and of the geographical distribution of the precipitation (Fig. 3) revealed that (i) heavy rainfall persisted for the entire observation period, hitting different parts of the promontory at different times, and that (ii) seven periods could be singled out, including four rainfall (wet) periods and three no-rainfall (dry or nearly dry) periods (Fig. 3). The rainfall periods ranged from 8 to $49 \mathrm{~h}$ and were separated by dry periods lasting between 11 and $19 \mathrm{~h}$ (Table 1).

The first rainfall period (I) lasted $8 \mathrm{~h}$, from 12:00 to 20:00 UTC +2 on 1 September. In this wet period, around $50 \mathrm{~mm}$ of rain was measured by most of the rain gauges, for 
Table 1. Characteristics of seven periods in the sequence of rainfall events that hit the Gargano Promontory between 1 and 6 September 2014. Start and end times are given in UTC+2. Rain/dry lists rainfall, wet (R) and no-rainfall, dry or nearly dry (D), periods. Rainfall gives the range (minimum-maximum) of the cumulated rainfall in each period. Intensity is the average intensity in the period for the maximum cumulated rainfall. See also Figs. 3 and 7.

\begin{tabular}{lllrlrr}
\hline \multirow{2}{*}{ Period } & Start & End & Length & Rain/dry & Rainfall & Intensity \\
\cline { 2 - 7 } & day, hour & day, hour & hour & & $\mathrm{mm}$ & $\mathrm{mm} \mathrm{h}^{-1}$ \\
\hline I & 1 Sep, 12:00 & 1 Sep, 20:00 & 8 & $\mathrm{R}$ & $20-50$ & 6.25 \\
II & 1 Sep, 20:00 & 2 Sep, 15:00 & 19 & $\mathrm{D}$ & $0-6$ & 0.31 \\
III & 2 Sep, 15:00 & 4 Sep, 16:00 & 49 & $\mathrm{R}$ & $50-440$ & 8.97 \\
IV & 4 Sep, 16:00 & 5 Sep, 04:00 & 12 & $\mathrm{D}$ & $0-6$ & 0.50 \\
V & 5 Sep, 04:00 & 5 Sep, 16:00 & 12 & $\mathrm{R}$ & $10-130$ & 10.83 \\
VI & 5 Sep, 16:00 & 6 Sep, 03:00 & 11 & $\mathrm{D}$ & $0-20$ & 1.82 \\
VII & 6 Sep, 03:00 & 6 Sep, 14:00 & 11 & $\mathrm{R}$ & $50-140$ & 12.73 \\
\hline
\end{tabular}

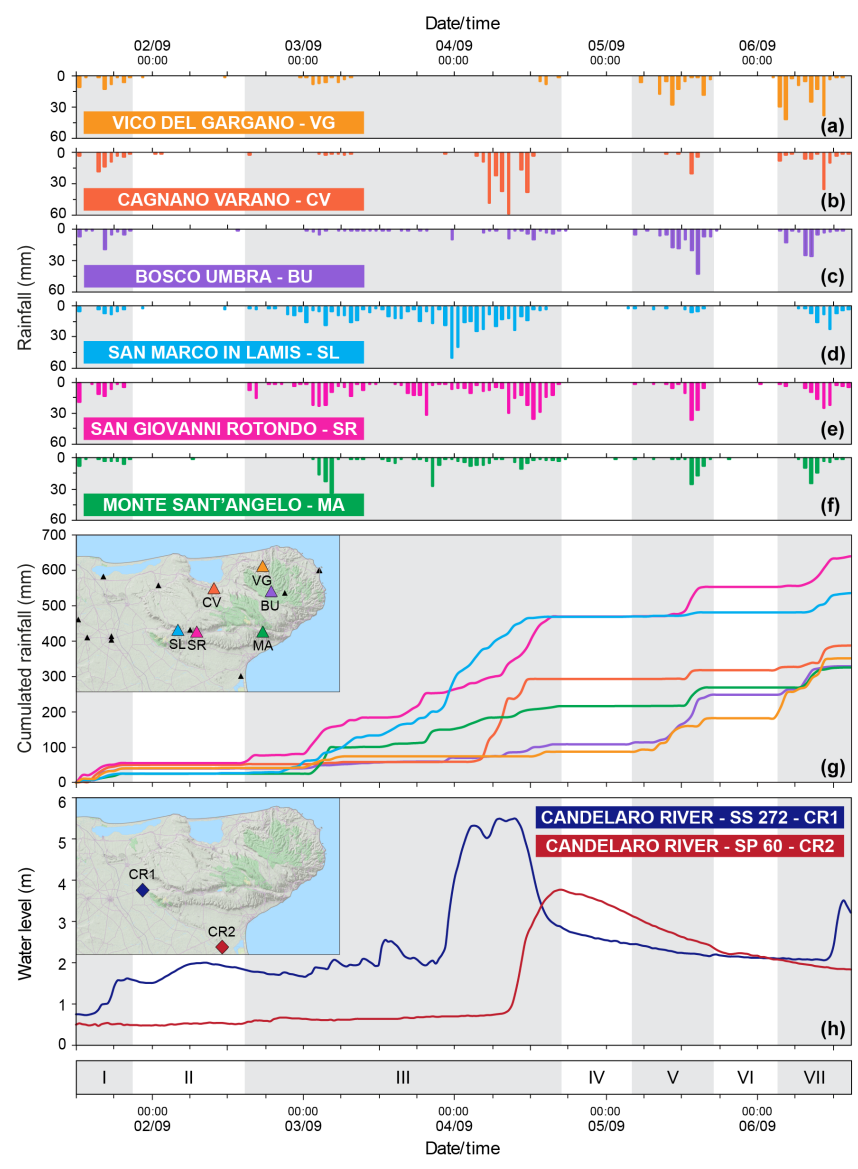

Figure 3. Rainfall and hydrological conditions for the period 1-6 September 2014 in the Gargano Promontory. (a-f) Hourly rainfall measurements for six rain gauges in the study area. (g) Cumulated rainfall for the same rain gauges; inset shows location of the rain gauges. (h) River water level at two gauging stations along the Candelaro River; inset shows location of gauging stations. In the charts, shaded areas are rainfall (wet) periods (I, III, V, VII) and white areas are no-rainfall (dry) periods (II, IV, VI). an average rainfall intensity of about $6.25 \mathrm{~mm} \mathrm{~h}^{-1}$ (Fig. 3, Table 1). After a period of $19 \mathrm{~h}$ without rainfall (II), the second rainfall period started (III) and was particularly severe in the SW part of the promontory. About $400 \mathrm{~mm}$ was measured at the San Giovanni Rotondo and the San Marco in Lamis rain gauges, corresponding to an average intensity exceeding $8.2 \mathrm{~mm} \mathrm{~h}^{-1}$, with peak values exceeding $40 \mathrm{~mm} \mathrm{~h}^{-1}$. Relatively smaller amounts of rainfall were recorded at the Cagnano Varano (240 mm, most of which between 05:00 and 12:00 UTC+2 on 4 September) and the Monte Sant'Angelo (200 $\mathrm{mm}$ ) rain gauges. The Vico del Gargano and the Bosco Umbra rain gauges, located in the NE part of the promontory, recorded approximately $50 \mathrm{~mm}$ of rain in the period (Figs. 1, 3).

Following a dry period of $12 \mathrm{~h}$ (IV), rainfall started again on 5 September (V), and this time it was most abundant in the NE part of the promontory. In this period, the Bosco Umbra and Vico del Gargano rain gauges measured slightly more and slightly less than $100 \mathrm{~mm}$ of rain, respectively, corresponding to a rainfall intensity exceeding $8.0 \mathrm{~mm} \mathrm{~h}^{-1}$. On the opposite, southern side of the promontory, the San Marco in Lamis rain gauge recorded only $10 \mathrm{~mm}$ of rainfall. In the same period (V), the San Giovanni Rotondo and Monte Sant'Angelo rain gauges, in the SE part of the promontory, measured about $50 \mathrm{~mm}$ of rainfall. Period V was followed by an $11 \mathrm{~h}$ nearly dry period (VI) which ended at 03:00 UTC+2 of 6 September 2014, when intense rainfall started again. The last rainfall period (VII) lasted until 14:00 UTC +2 . In the $11 \mathrm{~h}$ period all the considered rain gauges measured more than $50 \mathrm{~mm}$ of rain, with the maximum cumulated value recorded by the Vico del Gargano rain gauge, where $140 \mathrm{~mm}$ of rain was measured, corresponding to a rainfall intensity exceeding $12.0 \mathrm{~mm} \mathrm{~h}^{-1}$.

A rank analysis of rainfall measurements for six rain gauges in the 7-year period from April 2009 to April 2016, highlighted the severity of the 6-day rainfall period (Fig. 4). Except for the Monte Sant'Angelo rain gauge, located in the southern part of the promontory, the 1-6 September rainfall 

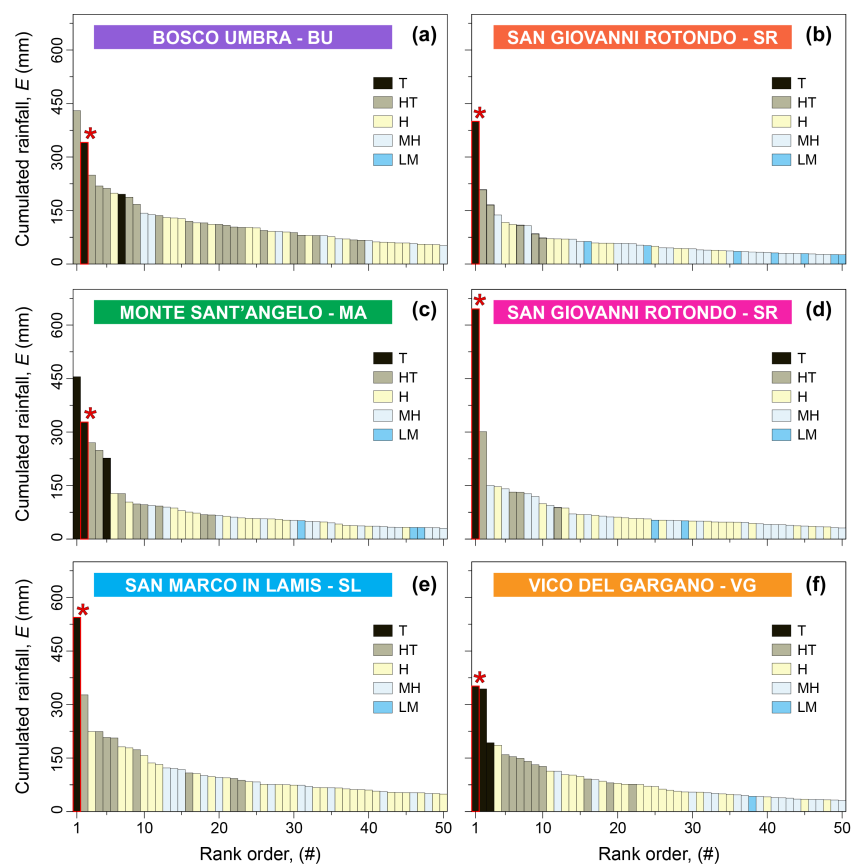

Figure 4. Rank order analysis of rainfall events in the Gargano Promontory from April 2009 to April 2016. Coloured bars show cumulated event rainfall for six rain gauges: (a) Bosco Umbra BU, (b) Cagnano Varano - CV, (c) Monte Sant'Angelo - MA, (d) San Giovanni Rotondo - SR, (e) San Marco in Lamis SM and (f) Vico del Gargano - VG. Bars arranged from high (left) to low (right) values. Colours identify six categories of cumulated rainfall proposed by Alpert et al. (2002). Legend: T is torrential rainfall (minimum $128 \mathrm{~mm} \mathrm{day}^{-1}$ ), HT is heavytorrential $\left(64-128 \mathrm{~mm} \mathrm{day}^{-1}\right), \mathrm{H}$ is heavy (32-64 $\left.\mathrm{mm} \mathrm{day}^{-1}\right), \mathrm{MH}$ is moderate-heavy $\left(16-32 \mathrm{~mm} \mathrm{day}^{-1}\right)$ and LM is light-moderate $\left(4-16 \mathrm{~mm} \mathrm{day}^{-1}\right)$. Black bars with red asterisks show the 1-6 September 2014 period.

period exhibited the highest cumulated rainfall in the observation period. Adopting the classification proposed by Alpert et al. (2002), the rainfall was "torrential" in all the considered rain gauges and, for three of the rain gauges, it was the only torrential event in the (short) record available (Fig. 4).

\subsection{Landslides, floods and sinkholes}

The sequence of intense rainfall events resulted in a number of floods, flash floods, landslides and sinkholes and caused two flood fatalities at Peschici and at Carpino (http://polaris. irpi.cnr.it/) and severe socio-economic damage (Fig. 5). Throughout the promontory, the road and railway networks were interrupted at several sites by inundations (Fig. 6a) and landslides, and many road underpasses were clogged by debris and sediments (Fig. 6b). In several towns and dwellings the inhabitants were evacuated from their homes, and a number of touristic resorts were inundated by water, mud and debris.

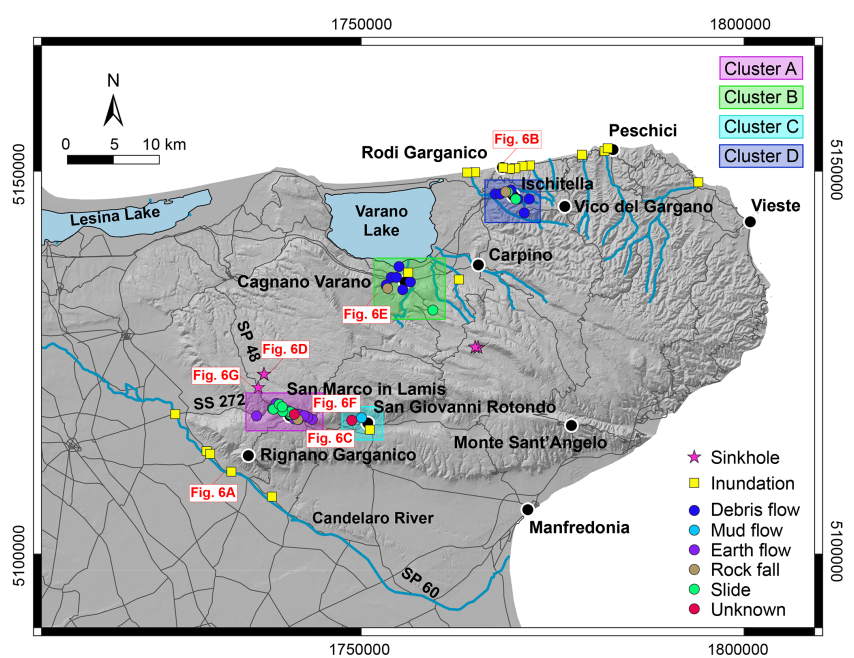

Figure 5. Map showing location of event landslides, floods and sinkholes triggered by the 1-6 September 2014 intense rainfall event in the Gargano Promontory. WGS84/Pseudo Mercator (EPSG:3857).

The consequences of the storm of September 2014 were reported soon after their occurrence, and a first analysis was carried out immediately in its aftermath. The collection of information was obtained searching different sources: (i) field surveys, (ii) technical reports produced by geologists, and (iii) online national, regional and local newspapers.

The collected information allowed the geographical coordinates of each phenomenon, its occurrence date and the type of hazard to be reconstructed.

No geological and geomorphological details were available for the landslides, especially when the information was found in newspapers. A specific landslide catalogue was built and managed in a GIS environment. The catalogue lists the following items: (i) event identification code, (ii) source of information, (iii) landslide location (geographic coordinates, municipality, province), (iv) occurrence date and time (if available), (v) spatial and temporal accuracy and (vi) landslide type.

As concerns floods, the main information consisted of the areas of interest, the reported damage and the extent of the flooded territory. Information on sinkholes included the occurrence site obtained through field surveys (high geographical accuracy) and the occurrence time, which was mostly based upon interviews with local inhabitants (low to medium temporal accuracy).

Flooding was widespread in the Candelaro catchment that bounds to the SW the Gargano Promontory (Fig. 5). Two hydrological gauging stations, one located where the Candelaro River crosses State Road SS 272 (W of the Gargano range) and one where it crosses the Provincial Road SP 60 near to the outlet in the Manfredonia Gulf (Fig. 5), measured very high water levels. The upstream gauge along the SS 272 measured a first peak of $5.30 \mathrm{~m}$ at $02: 00 \mathrm{UTC}+2$ on 

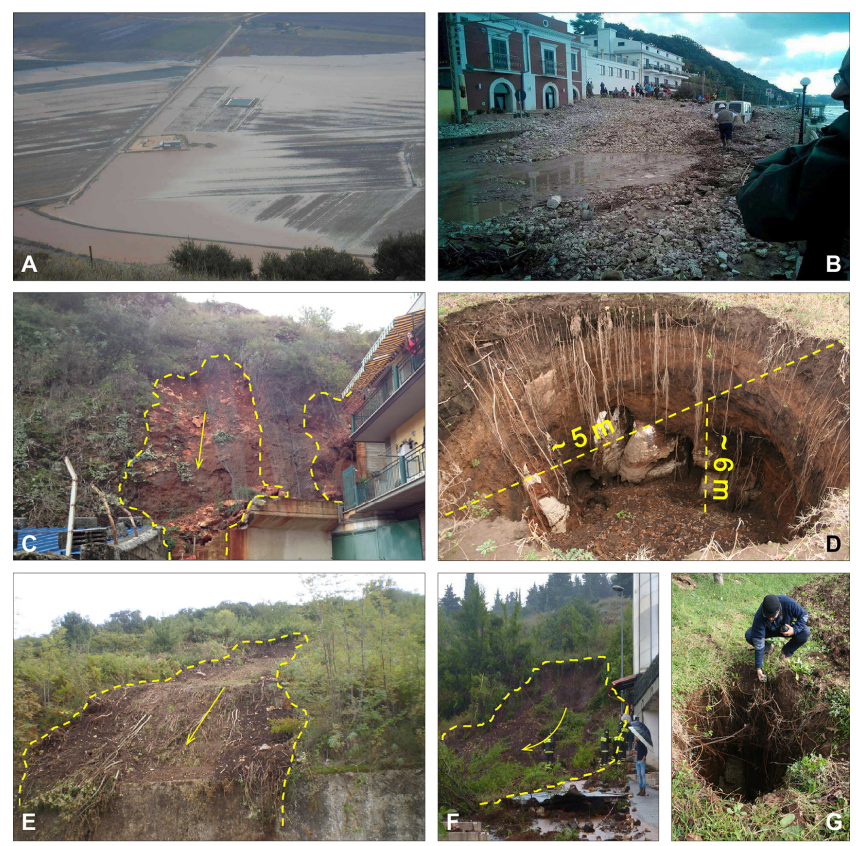

Figure 6. Examples of geohydrological hazards triggered by the 1-6 September 2014 torrential rainfall in the Gargano Promontory. (a) Flood plain inundated by the Candelaro River (photograph: Regione Puglia). (b) Inundation in Rodi Garganico (photograph: Regione Puglia). (c, f) Shallow landslides in the town of San Marco in Lamis. (d) Sinkhole in San Marco in Lamis (photograph: M. Parise). (e) Shallow landslide in Cagnano Varano (photograph: Regione Puglia). (g) Sinkhole in Monte Sant'Angelo (photograph: M. Parise).

4 September, followed by a slightly higher peak of $5.50 \mathrm{~m}$ at $06: 30 \mathrm{UTC}+2$. The water level remained very sustained until 09:00 UTC+2 and then it diminished (Fig. 3h). At the downstream gauging station located along SP 60, about 30 $\mathrm{km}$ downstream from the upstream gauge, a peak of $3.77 \mathrm{~m}$ was measured at 16:00 UTC +2 on 4 September, about $10 \mathrm{~h}$ later than the peak measured by the upstream gauge. We justify the (significant) time difference in the peak discharge by the widespread inundation of the Candelaro River plain (Fig. 6a).

Inundations were also severe along the northern coastal area, between Varano Lake and Vieste, and particularly between the towns of Cagnano Varano and Carpino (Fig. 5). Near Varano Lake, large agricultural areas were inundated. Along the northern coast of the promontory, flash floods produced by small torrents occurred mostly on 5-6 September. In the morning of 5 September, the Macchio Torrent overflowed and inundated Vieste, and several touristic sites. Overflowing of minor torrents and ditches was reported in the early hours of 6 September in the towns of Peschici, Vico del Gargano and Rodi Garganico.

The torrential rain caused a number of landslides, mostly shallow landslides (Fig. 6c, e, f). Overall, we collected in- formation on 46 landslides, including 14 earthflows, 14 debris flows, 11 soil slides, 4 rockfalls, 1 mudflow and 2 slope failures of undetermined type. This is a subset of all the event landslides in the Gargano Promontory. Based on the type of failures, we hypothesise that all the landslides were from rapid to extremely rapid. Most of the mapped landslides were in the municipalities of San Marco in Lamis, Ischitella and Cagnano Varano. Landslides were also reported near San Giovanni Rotondo, Rignano Garganico and Rodi Garganico (Fig. 5).

We searched information on the time or period of occurrence of the landslides. However, for most of the landslides the time or period of occurrence remains unknown or suffers from very large uncertainty. For only nine landslides we obtained reasonably accurate information on the period of occurrence of the slope failures. On 3-4 September, four landslides occurred near San Marco in Lamis, along SS 272, most probably in the $3 \mathrm{~h}$ period between 23:00 and 02:00 UTC +2 . We consider these landslides representative of a larger cluster in the same area (cluster A). On 4 September, a landslide occurred between 05:00 and 16:00 UTC +2 near Cagnano Varano (cluster B). In the same day, a single landslide occurred in the municipality of San Giovanni Rotondo at an undetermined time between 14:00 and 21:00 UTC +2 (cluster C). Lastly, three landslides occurred in the night between 5 and 6 September and most probably between 23:00 and 05:00 UTC+2, in the municipalities of Ischitella and Rodi Garganico (cluster D). We attribute the scarce temporal information and the poor accuracy of the information on the time of occurrence of the failures to the difficulty of reaching some of the places where the landslides occurred and to the fact that many landslides occurred in the evening or during the night and were reported only several hours after the event.

The torrential rainfall also caused sinkholes. We mapped 10 small sinkholes near the villages of San Marco in Lamis and Monte Sant'Angelo (Fig. 5). Based on their morphology and shape, the sinkholes were classified as collapse or cover-collapse sinkholes (Gutiérrez et al., 2008, 2014). At San Marco in Lamis, four sinkholes affected the lower part of a pre-existing karst depression. The deepest sinkhole was about $6 \mathrm{~m}$ deep, $5 \mathrm{~m}$ wide and exposed limestone and residual terra rossa deposits that represent the upper part of the epikarst (Williams, 2008) (Fig. 6d). Other sinkholes were less developed and were detected and mapped locally only based upon morphological considerations. Due to the remote areas where the sinkholes occurred, their limited sizes (Fig. $6 \mathrm{~g}$ ) and the difficulty of detecting them, no accurate information is available on the time or period of occurrence of the sinkholes. 


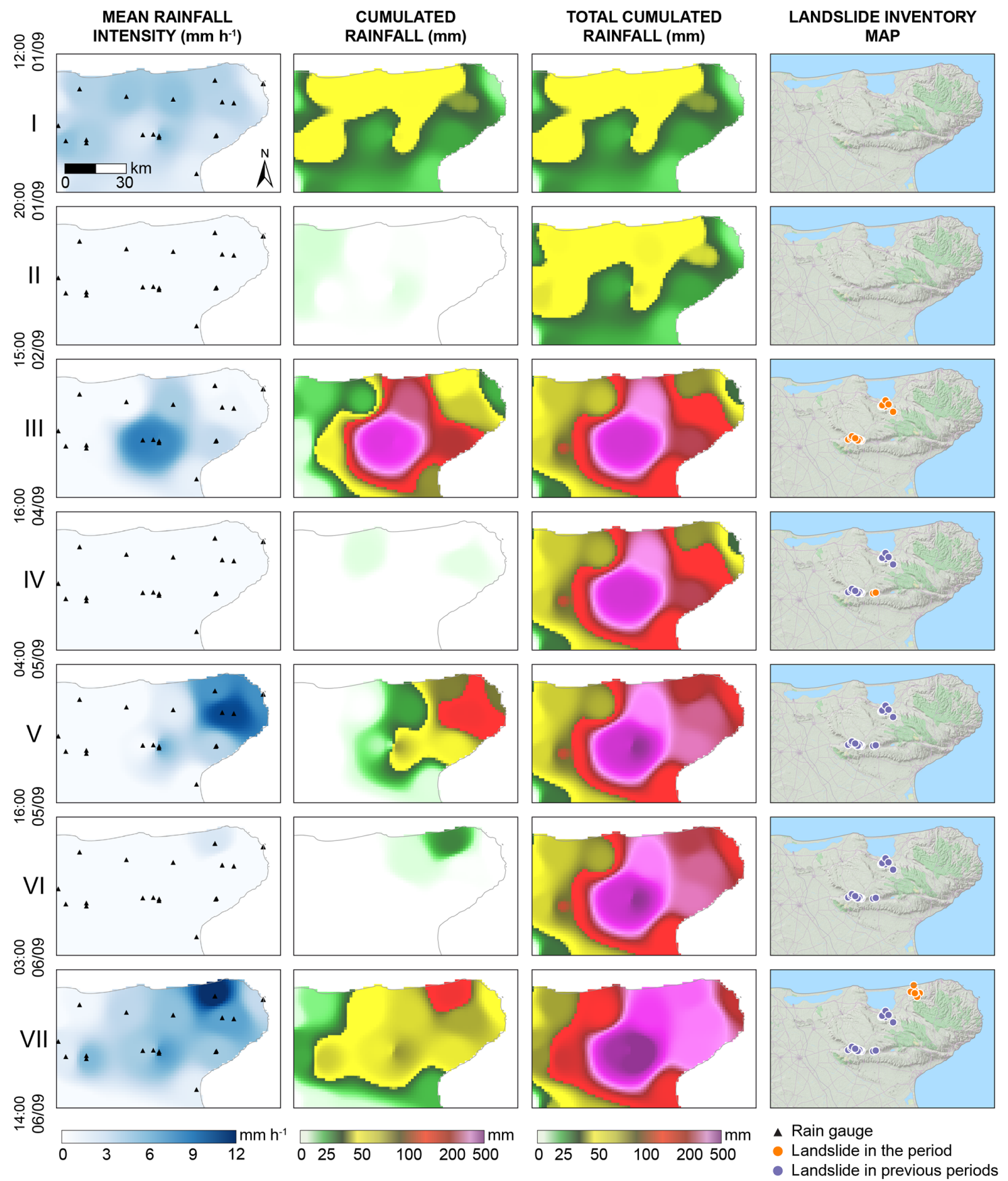

Figure 7. Analysis of the spatial and temporal distribution of the event rainfall and of the triggered event landslides. See text for explanation.

\subsection{Spatial and temporal distributions of rainfall and geohydrological hazards}

To help investigate the effect of the changing spatial and temporal distribution of the rainfall on the location of the landslides, floods and sinkholes, we prepared Fig. 7, which portrays, for each period in the sequence of rainfall events (Sect. 3.2), maps showing the spatial distributions of the mean rainfall intensity (in $\mathrm{mm} \mathrm{h}^{-1}$ ), the cumulated rainfall for the single period and from the beginning of the event (in $\mathrm{mm}$ ) and the location of the landslides that occurred in each period and in previous periods.

An inspection of Fig. 7 reveals that the total cumulated rainfall, exceeding $100 \mathrm{~mm}$ in large parts of the promontory, was the result of separate rainfall events that hit different parts of the promontory at different times. The first rainy period (I) was more widespread but characterised by an overall moderate cumulated rainfall not exceeding $50 \mathrm{~mm}$ 
and rainfall intensity not exceeding $6.2 \mathrm{~mm} \mathrm{~h}^{-1}$. No landslides or floods were reported during the first rainy period. The second (III) and the third (V) rainy periods were more localised; the second was in the central part of the promontory (San Marco in Lamis and San Giovanni Rotondo) and the third was in the NE sector of the promontory (Ischitella, Vico del Gargano and Vieste), and were both characterised by high values of cumulated rainfall (exceeding $400 \mathrm{~mm}$ in the second and $130 \mathrm{~mm}$ in the third period) and of rainfall intensity ( exceeded $8.5 \mathrm{~mm} \mathrm{~h}^{-1}$ for the second period and $10.5 \mathrm{~mm} \mathrm{~h}^{-1}$ for the third period, respectively). Landslides were reported in the central (cluster A) and in the northern (cluster B) parts of the promontory during the second rainfall period (III). In the same period the upstream hydrological gauging station along the Candelaro River measured high water flows exceeding $5.0 \mathrm{~m}$ (Fig. 2), about $2 \mathrm{~h}$ after the maximum hourly rainfall measured at the San Marco in Lamis rain gauge, at 24:00 UTC +2 on 3 September. The landslides occurred in areas where the total event cumulated rainfall exceeded $400 \mathrm{~mm}$ (for cluster A) and $200 \mathrm{~mm}$ (for cluster B).

In the central part of the promontory, landslides were also reported (cluster C) during the second dry period (IV). Given the poor temporal accuracy of these landslides (i.e. between 14:00 and 21:00 UTC +2 on 4 September), we cannot exclude that the failures occurred during the last few hours of the previous rainfall period (III). The hypothesis is supported by the fact that the San Giovanni Rotondo rain gauge measured rainfall until 15:00 UTC+2 on 4 September (Fig. 2). The last rainfall period (VII) was again characterised by widespread rainfall throughout most of the promontory with a distinct peak in the NE sector exceeding $130 \mathrm{~mm}$. Where rainfall intensity was particularly intense $\left(>11 \mathrm{~mm} \mathrm{~h}^{-1}\right)$ in the NE part of the promontory, between Rodi Garganico and Peschici, landslides were also reported (cluster D).

\section{Geohydrological hazards forecasting algorithm}

We used the rainfall records and hazard information available for the Gargano event to design and test an algorithm for the possible operational forecasting of rainfall-induced landslides and other geohydrological hazards, including flash floods and sinkholes

\subsection{The E-NEP algorithm}

The ensemble-non-exceedance probability (E-NEP) algorithm exploits a standard rainfall record obtained by a rain gauge to trace in time the probability of possible landslide occurrence and of related geohydrological hazards. For the purpose, for each time $t_{i}$, E-NEP calculates the event rainfall duration $D$, and the corresponding event cumulated rainfall $E$, for increasing antecedent periods before $t_{i}$, from $t_{i}$ to $t_{i}+T$, in $d$ time steps, with $T$ the maximum length of the considered antecedent rainfall period and $d$ the time step used to increment the duration of the antecedent rainfall period. For each rainfall-duration-event-cumulated-rainfall pair the corresponding non-exceedance probability (NEP) $p(D, E)$ is obtained using the probabilistic approach proposed by Brunetti et al. (2010) and modified by Peruccacci et al. (2012) for the definition of empirical rainfall thresholds for possible landslide occurrence (Guzzetti et al., 2007). The set of the NEP values (i.e. $\{\mathrm{NEP}\}=\{p(D, E)\}$ ) is then used to determine an ensemble of metrics, including the maximum value of the NEP $\left(\mathrm{NEP}_{\max }\right)$, the 10th, 25th, 50th, 75th and 90th percentiles $\left(\mathrm{NEP}_{10}, \mathrm{NEP}_{25}, \mathrm{NEP}_{50}, \mathrm{NEP}_{75}\right.$, $\left.\mathrm{NEP}_{90}\right)$, and the rainfall duration $\left(D_{\mathrm{NEP} m a x}\right)$ associated with $\mathrm{NEP}_{\text {max }}$, that collectively are exploited for landslide forecasting. The process is repeated at regular time intervals $(z$, where $t_{i+1}=t_{i}+z$ ), allowing the temporal evolution of the probability of possible occurrence of rainfall-induced landslides and of related geohydrological hazards to be followed.

Figure 8 portrays the logical schema for the E-NEP algorithm, which consists of two nested loops. First, the maximum length of the considered rainfall period, $T$ (in hours), the time step to increment the duration of the considered antecedent rainfall, $\mathrm{d}$ (in hours) and the time interval before the next set of $(D, E)$ pairs is computed, $z$ (in hours), are set to user-defined values. We stress that the three time (duration) variables are independent, with the only constraint that $d \leq T$. Next, the external loop (cyan in Fig. 8) starts, the rainfall duration $D$ is set to $d$ and $\{\mathrm{NEP}\}$ is set to null (an empty set). Next, the internal loop (orange in Fig. 8) starts and for the given rainfall duration $D$, the corresponding cumulated rainfall $E$ is determined, and the probability of landslide occurrence $p(D, E)$ is computed adopting the method proposed by Brunetti et al. (2010) and Peruccacci et al. (2012) and stored in $\{\mathrm{NEP}\}$. The rainfall duration $D$ is then incremented $(D=D+d)$ and tested to verify whether it is larger than $T$. If $D \leq T$, the internal loop is repeated using the current value of $D$ and the corresponding $E$; otherwise $(D>T)$ the loop ends, and the ensemble of metrics of $\{\mathrm{NEP}\}\left(\mathrm{NEP}_{10}, \mathrm{NEP}_{25}, \mathrm{NEP}_{50}, \mathrm{NEP}_{75}, \mathrm{NEP}_{90}, \mathrm{NEP}_{\max }\right)$ and the value of $D_{\text {NEPmax }}$ are calculated. The external loop is then repeated after the user-defined time interval of $z$ hours.

Figure 9 exemplifies the application of the E-NEP algorithm to a specific rainfall record, at a given time $t_{i}$ (i.e. the application of the orange internal loop of Fig. 8), for an antecedent period $T=96 \mathrm{~h}$, with $d=1 \mathrm{~h}$. E-NEP calculates the cumulated event rainfall $E$ for increasing durations $D$ from 1 $\left(t_{i}-1\right)$ to $96 \mathrm{~h}\left(t_{i}-96\right)$, every hour (time step $\left.d=1\right)$. The individual $(D, E)$ pairs are plotted as grey dots in Fig. 9d. For each pair, the corresponding NEP, the non-exceedance probability of possible landslide occurrence, was calculated and is shown by the blue squares in Fig. 9d. To further clarify the operations performed by the E-NEP algorithm, the bar charts in Fig. 9a, b, c show, for the same time $t_{i}$, three antecedent rainfall periods corresponding to durations of $D=6 \mathrm{~h}$ (red bars), $D=16 \mathrm{~h}$ (green bars) and $D=44 \mathrm{~h}$ (yellow bars). The corresponding cumulated event rainfall (red, green, yellow 


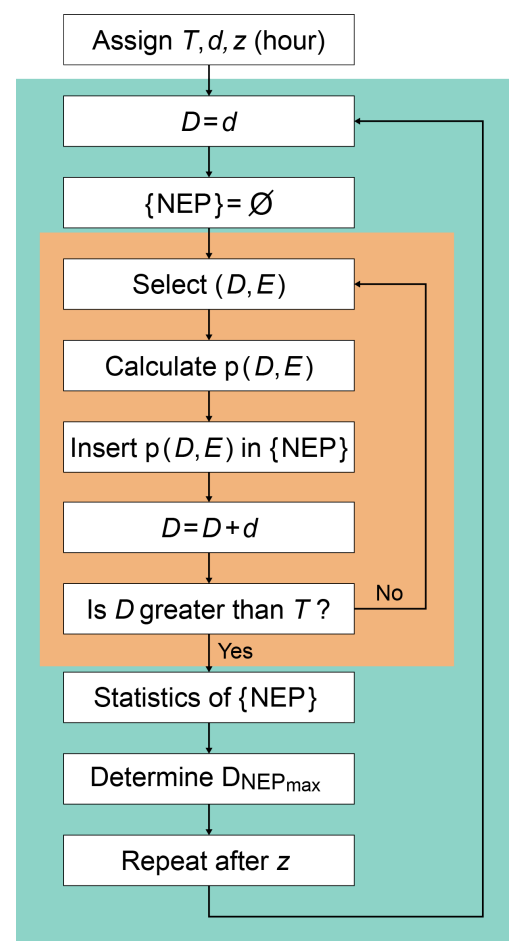

Figure 8. Logical scheme for the E-NEP algorithm. $D$ is rainfall duration in hours. $E$ is cumulated rainfall in milimetres. $T$ is maximum length of the considered rainfall period in hours. $d$ is the time step used to increment the duration of the rainfall period, up to $T$ in hours. $z$ is the time interval before the next set of $(D, E)$ pairs is computed, in hours. $\{\mathrm{NEP}\}$ is the set of non-exceedance probability (NEP) values obtained for each $(D, E)$ pair adopting the method proposed by Brunetti et al. (2010) and Peruccacci et al. (2012). Statistics of $\{\mathrm{NEP}\}$ are 10th, 25th, 50th, 75th and 90th percentiles. and $\mathrm{NEP}_{\max }$ is the maximum value of NEP. $D_{\mathrm{NEPmax}}$, event rainfall duration corresponding to $\mathrm{NEP}_{\max }$. External (blue) loop is run every $z$ hours or fraction of hour. Internal (orange) loop runs from $d$ to $T$, in $d$ time steps. In Figs. 9, $10 z$ and $d$ were set to $1 \mathrm{~h}$ and $T$ to $96 \mathrm{~h}$. See text for explanation.

circles) and the associated non-exceedance probability values (red, green, yellow squares) are shown in Fig. 9d. Lastly, the box plot to the right of Fig. 9d portrays (i) the ensemble of metrics of $\{\mathrm{NEP}\}: \mathrm{NEP}_{10}, \mathrm{NEP}_{25}, \mathrm{NEP}_{50}, \mathrm{NEP}_{75}$ and $\mathrm{NEP}_{90}$ and the maximum value of the non-exceedance probability, $\mathrm{NEP}_{\max }$. In Fig. 9d, the green square identifies $\mathrm{NEP}_{\max }$, i.e. the non-exceedance probability corresponding to the most critical rainfall condition for possible landslide occurrence in the considered rainfall period. The corresponding duration ( $D=16 \mathrm{~h}$ ) represents the $D_{\text {NEPmax }}$ value.

\subsection{Application and discussion of the E-NEP algorithm}

We applied the E-NEP algorithm to the 13-day period between 31 August and 12 September, which encompasses the entire series of rainfall events that hit the Gargano Promontory. We applied the algorithm to synthetic hourly rainfall records reconstructed for the locations of the four spatial-temporal landslide clusters identified in the study area (Fig. 7). To reconstruct the synthetic rainfall records, we interpolated the hourly rainfall measurements obtained by 39 rain gauges in the Gargano Promontory and the surrounding regions at the landslide locations. For that purpose, we used a standard inverse weighted distance (IDW) spatial interpolator (Shepard, 1968) to obtain hourly rainfall values on a regular $500 \mathrm{~m} \times 500 \mathrm{~m}$ grid. Next, the hourly rainfall grids were sampled at the grid cells selected to represent the four landslide clusters A, B, C and D, and the synthetic hourly rainfall time series were reconstructed for each landslide cluster.

For our analysis, and for each landslide cluster, $t_{i}$ ranged from 31 August, 00:00 UTC +2 to 11 September, 24:00 UTC +2 , in regular $1 \mathrm{~h}$ time intervals $(z)$, corresponding to a total of 288 time intervals. For each $t_{i}$, E-NEP computed the $\mathrm{NEP}_{10}, \mathrm{NEP}_{25}, \mathrm{NEP}_{50}, \mathrm{NEP}_{75}$ and $\mathrm{NEP}_{90}$ percentiles, the $\mathrm{NEP}_{\max }$ and the corresponding $D_{\mathrm{NEPmax}}$.

Results of the analysis of the four landslide clusters are shown in Fig. 10, in which the single plots show, from top to bottom, the temporal evolution of (i) the measured and the cumulated rainfall, (ii) the $\mathrm{NEP}_{10}, \mathrm{NEP}_{25}, \mathrm{NEP}_{50}, \mathrm{NEP}_{75}$, $\mathrm{NEP}_{90}$ percentiles (shown in ranges, by two different shades of blue and by the thick blue line) and $\mathrm{NEP}_{\max }$ (purple line) and (iii) the corresponding $D_{\text {NEPmax }}$ (green line). Figure 10 also shows (i) with grey areas, the possible period of occurrence of the landslides, a measure of the uncertainty in the failure occurrence time and (ii) with a vertical blue line the time of the high peak measured by the Candelaro gauge along SS 272 (Fig. 10a, Fig. 3).

For cluster A, encompassing landslides occurred along State Road SS 272 and SP 48 near San Marco in Lamis; a short rainfall burst hit the landslide area at 12:00 UTC +2 on 1 September and stopped shortly afterward (Fig. 10a1, I in Fig. 3). In this period, the $\mathrm{NEP}_{\max }$ increased rapidly to 0.15 and decreased immediately afterwards due to a lack of rainfall (Fig. $10 \mathrm{a}$ ). Next, following a dry period of $19 \mathrm{~h}$ (II in Fig. 3), the main rainfall event started at 16:00 UTC +2 on 2 September (Fig. 10a1, III in Fig. 3). As a result of this second, intense rainfall event all the NEP percentiles increased abruptly and significantly (Fig. 10a2), with $\mathrm{NEP}_{\max }$ exceeding 0.99 at 23:00 UTC +2 on 3 September. The landslides of cluster A followed shortly afterward.

Following the landslide occurrence, all the NEP values remained high for $12 \mathrm{~h}$. When the rainfall stopped, at 14:00 UTC +2 on 4 September, the NEP percentiles decreased, beginning with NEP10 and continuing with the other (larger) percentiles. $\mathrm{NEP}_{\max }$ decreased below 0.25 at 21:00 UTC +2 on 8 September. The analysis of the temporal trend of $D_{\text {NEPmax }}$ (Fig. 10a3), the rainfall duration corresponding to largest NEP, is of interest. $D_{\text {NEPmax }}(\mathrm{i})$ increased in response to the first rainfall period (I in Fig. 3), (ii) kept rising during the first dry period (II in Fig. 3), (iii) dropped to zero during the second (main) rainfall period and precisely when the rainfall intensity reached a maximum value 

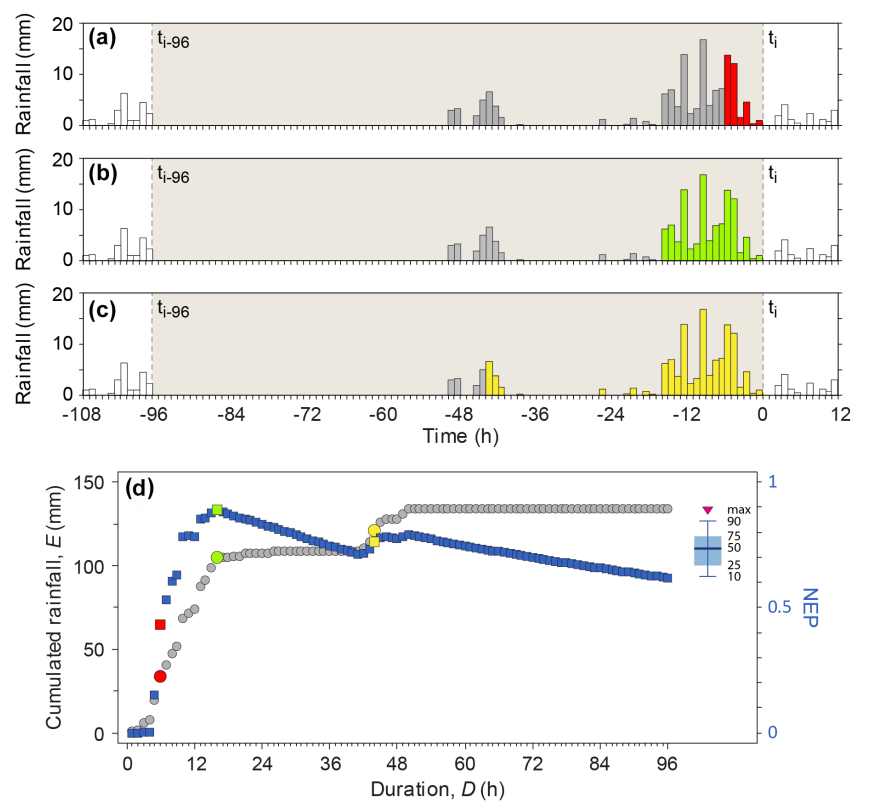

Figure 9. Exemplification of the E-NEP algorithm used to provide a non-exceedance probability (NEP) of possible landslide occurrence. Panels (a), (b) and (c) show the same rainfall record and three antecedent conditions corresponding to durations of (a) $D=6 \mathrm{~h}$ (red bars), (b) $D=16 \mathrm{~h}$ (green bars) and (c) $D=44 \mathrm{~h}$ (yellow bars). Panel (d) shows rainfall $(D, E)$ pairs (grey dots); red, green and yellow dots represent the $(D, E)$ pairs corresponding to the conditions shown in (a), (b) and (c). Blue squares show the corresponding nonexceedance probabilities (NEP). Green square represents $\mathrm{NEP}_{\max }$. See text for explanation.

of $7 \mathrm{~mm} \mathrm{~h}^{-1}$ (III in Fig. 3), (iv) increased steadily for $94 \mathrm{~h}$ and (iv) remained high until almost the end of the considered period.

We observe that landslides in cluster A occurred when the $\mathrm{NEP}_{\max }$ was close to its maximum possible value $\left(\mathrm{NEP}_{\max }=1\right)$, a very critical condition for possible landslide initiation (Brunetti et al., 2010; Peruccacci et al., 2012). Just before the landslide occurrence (i) $\mathrm{NEP}_{50}$ was close to $\mathrm{NEP}_{\max }$; i.e. the median value was close to the maximum value of the non-exceedance probability, (ii) the interpercentile ranges $\mathrm{NEP}_{10}-\mathrm{NEP}_{90}$ and $\mathrm{NEP}_{25}-\mathrm{NEP}_{75}$ were narrow and (iii) there was a sudden increase of all NEP values, particularly of the lower percentiles (i.e. $\mathrm{NEP}_{10}, \mathrm{NEP}_{25}$ ) (Fig. 10a2). We further observe that landslides in this cluster occurred after $D_{\text {NEPmax }}$ began to rise following a sudden drop (Fig. 10a3).

Inspection of the other plots in Fig. 10 reveals significant similarities in the temporal evolution of the metrics computed by the E-NEP algorithm for the other three landslide clusters, when compared to the same metrics computed for cluster A. Specifically, (i) all landslides occurred when the NEPmax was close to its maximum value, and immediately before landslide occurrence (ii) NEP50 was close to NEP- max, (iii) the range NEP25-NEP75 was narrow, (iv) there was a sudden increase of all NEP percentiles (Fig. 10a2) except NEP10 (Fig. 10c2) and (v) the landslides occurred after the DNEPmax had started to rise following a previous sudden drop. We consider these observations diagnostic of the rainfall conditions that have resulted in landslides (and other geohydrological hazards) in the Gargano Promontory in the period 1-6 September 2014.

\section{Discussion}

The analysis of the rainfall records and the geohydrological hazard information available for the Gargano Promontory rainfall events between 1 and 6 September 2014 (Sect. 3) and their application to test the ensemble-non-exceedance probability (E-NEP) algorithm (Sect. 4) allows for general and specific considerations.

We first observe that landslides in the four examined clusters occurred for different levels of the cumulated event rainfall, $E$ (Fig. 7, Table 1). We also observe that rainfall intensity was very high in the period of the failures or immediately before it, but also that periods of high rainfall intensity were not associated with (known) landslides (see e.g. clusters C and D; Fig. 10b, c). We conclude that, in the case of the investigated rainfall events, single metrics like the event cumulated rainfall $E$ and the rainfall intensity $I$, on their own, were not singularly diagnostic of the rainfall conditions that have resulted in the known landslides.

As discussed in Sect. 4.2, a number of potentially diagnostic observations drawn from the ensemble of metrics produced by the E-NEP algorithm were common to all the examined landslide clusters, including the facts that (i) all the landslides occurred when $\mathrm{NEP}_{\max }$ was close to its maximum possible value, and that (ii) shortly before landslide occurrence there was a sudden increase in all NEP percentiles (except $\mathrm{NEP}_{10}$ locally, Fig. 10c2), $\mathrm{NEP}_{50}$ was close to $\mathrm{NEP}_{\max }$, and the interquartile range $\mathrm{NEP}_{25}-\mathrm{NEP}_{75}$ was narrow. Following landslides occurrence, $\mathrm{NEP}_{\max }$ remained typically sustained for long periods, but the NEP percentiles dropped more or less rapidly, even when additional rainfall fell in the area. We observe that no information on landslide occurrence was reported when $\mathrm{NEP}_{50}$ was low or very low. A further observation is that landslides occurred shortly after the $D_{\mathrm{NEPmax}}$ had started to rise following a previous drop. A sudden drop of $D_{\text {NEPmax }}$ is always related to an increase in $\mathrm{NEP}_{\max }$ that is determined by an increase in the rainfall intensity. However, a small increase in rainfall intensity may not be sufficient to cause $D_{\text {NEPmax }}$ to drop. We argue that visual analysis of the temporal evolution of $D_{\text {NEPmax }}$ can be exploited to provide indications of the rapid change of the possible critical rainfall conditions that may lead to slope failures shortly afterwards.

We conclude that the ensemble of the metrics produced by the E-NEP algorithm provides better diagnostic results than the single metrics often used for landslide forecasting, in- 
(a)
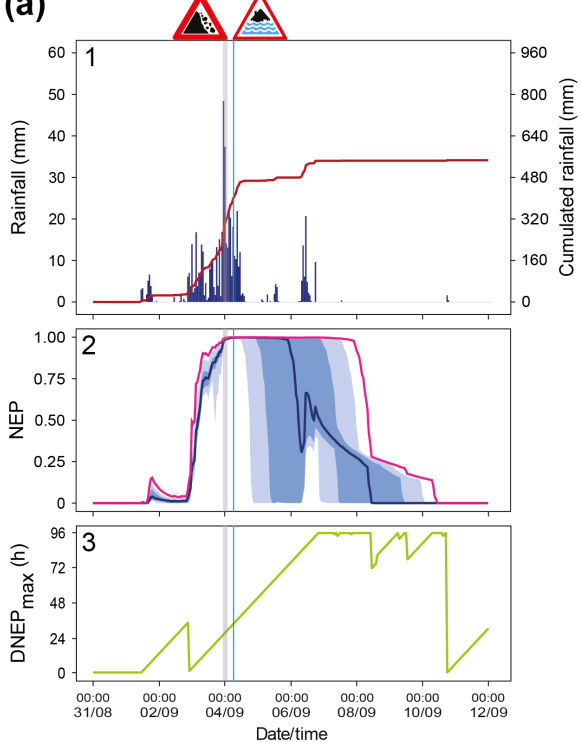

(c)
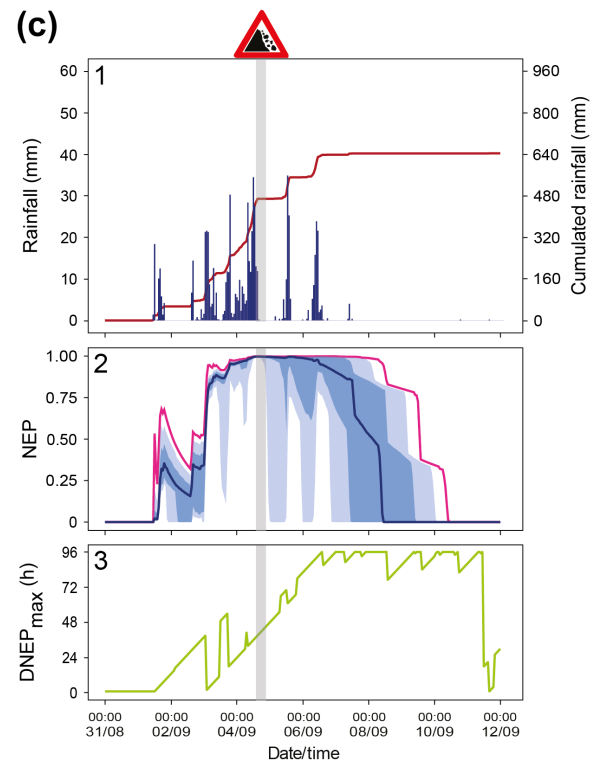

(b)
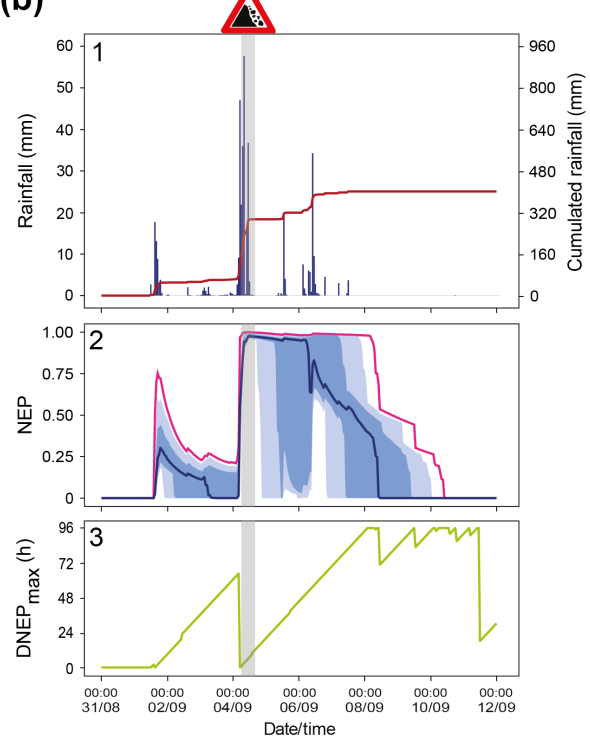

(d)
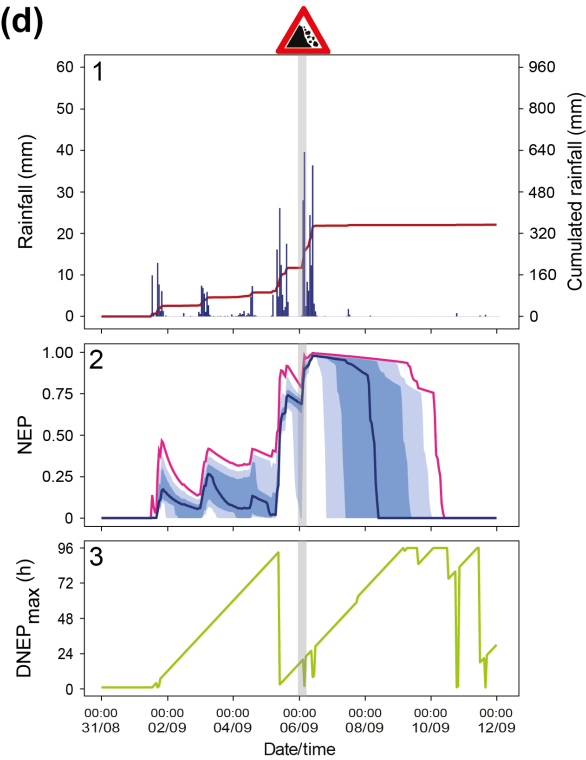

Figure 10. Results of the application of the E-NEP algorithm to synthetic rainfall records reconstructed for the locations of four landslide clusters. (a) Landslide cluster A, (b) landslide cluster B, (c) landslide cluster C, (d) landslide cluster D. Each panel shows, from top to bottom,

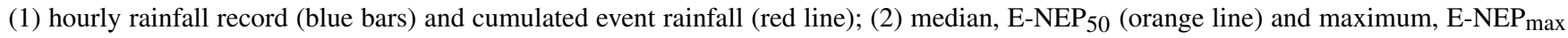
(purple line) values of the non-exceedance probability with ranges E-NEP $25-\mathrm{E}_{2} \mathrm{NEP}_{75}$ (dark blue shade) and $\mathrm{E}_{-} \mathrm{NEP}_{10}-\mathrm{E}_{-\mathrm{NEP}} \mathrm{N}_{90}(\mathrm{light} \mathrm{blue}$ shade); (3) rainfall duration corresponding to the most critical rainfall condition, D-NEP $\max$ (green line). The period of occurrence of the landslides (identified by the landslide road sign) is shown by a grey shaded area. The occurrence time (and the associated uncertainty) of nine landslides (cf. Sect. 3.3) is used to define the landslide occurrence period of the four clusters. The time of occurrence of peak flow (identified by the flood road sign) is shown by the vertical blue line. See text for explanation.

cluding rainfall duration, cumulated event rainfall and rainfall intensity (Guzzetti et al., 2007). This is visually portrayed in Fig. 10, where the temporal trend of the cumulated rainfall is less diagnostic than the corresponding trends of the $\mathrm{NEP}_{\max }$ or the $D_{\text {NEPmax }}$ in forecasting the periods of landslide occurrence.
We maintain that the E-NEP algorithm is potentially useful for near-real-time landslide warning, but we acknowledge that more investigations are required to test the algorithm in different meteorological, geological and physiographical settings. The sequences of closely spaced rainfall events in the Gargano Promontory covered a long period (6 days), and this made it particularly well suited for the design and testing of 
the E-NEP algorithm. The sequence of rainfall events was also the result of a relatively simple meteorological setting. More tests are needed to evaluate the performance of the ENEP algorithm for shorter and longer rainfall periods, and in different and more complex meteorological conditions.

We stress that the E-NEP algorithm was designed to attempt to forecast rainfall conditions for the possible occurrence of landslides that react rapidly to a rainfall input. These are typically shallow landslides, including soil slides and debris flows. E-NEP was not designed to attempt to evaluate other landslides that react slowly or very slowly to a rainfall input, including, for example, deep-seated landslides, shallow landslides in stiff clay. Also, E-NEP was not designed to attempt to predict landslides caused by meteorological triggers other than intense rainfall, including, for example, rainon-snow events or rapid snow-melt events. However, we expect that E-NEP can be adapted to forecast shallow landslides caused by intense rainfall even in specific, local conditions (e.g. in areas burnt by wildfires; Cannon et al., 2010; De Graff et al., 2013; Moody et al., 2013), provided that sufficient information is available to apply the method proposed by Brunetti et al. (2010) and Peruccacci et al. (2012).

Analysis of the rainfall conditions that have resulted in landslides, flash floods, inundation and sinkholes in the investigated period in the Gargano Promontory revealed that the geohydrological hazards occurred in response to extreme rainfall conditions. This is confirmed by the fact that (i) rainfall was torrential (Alpert et al., 2002) (Fig. 4) and (ii) the geohazards - and particularly the landslides - occurred when all the NEP percentiles were close to the possible maximum value of the non-exceedance probability of possible landslide occurrence (Fig. 10), which represent very severe rainfall conditions. The available record of historical landslides and floods indicates that these are not very frequent or abundant compared to other areas in southern Italy. We conclude that in the Gargano Promontory meteorologically driven hazards occur in response to extreme (i.e. rare) meteorological conditions. For rainfall-driven hazards, the landscape in the Gargano Promontory exhibits a threshold behaviour that can be modelled conceptually by a Heaviside step function (Abramowitz and Stegun, 1972). For light to heavy rainfall events (Alpert et al., 2002) geohydrological hazards do not occur or are rare and minor, whereas for heavy-torrential to torrential rainfall events they are abundant and particularly disruptive. We attribute the threshold-based behaviour to the karst environment that dominates the landscape in the promontory.

In the karst environment of the promontory, rainfall infiltration is efficient even for high-intensity rainfall rates. This limits the occurrence of landslides, except for very intense (i.e. extreme) rainfall events. On the other hand, the arrival of a great amount of rainfall in a setting typically characterised by water infiltrating within the rock mass through the network of conduits and joints highly facilitates the formation of flash floods, particularly in small catchments, as has been fre- quently registered also in other parts of Puglia (Parise, 2003; Mossa, 2007). Further, karst aquifers have very poor retention capacity. These and other characteristics allow the flash floods to be identified as one of the main hazards in karst terrains (Fleury et al., 2013; Gutierrez et al., 2014; Parise et al., 2015).

In the sinkholes, the presence of residual soils varies largely, depending on the location, size and depth of the sinkholes. Where the infiltration is reduced, partial or total inundation of the sinkholes occurs. These local inundations are difficult to detect because they last only for short periods and because they often go unnoticed in the rural, scarcely populated landscape of the promontory.

The torrential rainfall has triggered sinkholes in the Gargano Promontory (Fig. 6d, g). Accurate information on the time or period of occurrence of the sinkholes is not available, and even the simple detection of the sinkholes was hampered by their small size and the remote location of the events. However, sinkholes represent a subtle and serious hazard in the promontory and in other karst areas (Parise and Gunn, 2007; Gutierrez et al., 2014; Parise et al., 2015), and establishing methods and procedures for their possible forecasting is of primary interest in karst environments. Based on the analysis of the 1-6 September 2014 Gargano rainfall period, we confirm that in the promontory, and in similar karst areas, torrential rainfall can trigger sinkholes, and we hypothesise that approaches based on the near-real-time monitoring of rainfall (e.g. the E-NEP algorithm) can be used to forecast the possible occurrence of rainfall-induced sinkholes. We acknowledge that an analysis of a larger number of events is required to test this hypothesis.

\section{Conclusions}

We studied a period of torrential rain between 1 and 6 September 2014 in the Gargano Promontory, Puglia, southern Italy, which caused a variety of geohydrological hazards, including landslides, flash floods, inundations and sinkholes. We obtained information on the location of the events through field surveys and the analysis of anecdotal information obtained from various sources. The temporal information varied among the hazards. For inundations the time or period of occurrence were known from gauge data (Fig. 3h), and for flash floods from anecdotal sources (Fig. 6a, b). For landslides, the period of occurrence was inferred from anecdotal sources for only nine (out of 46) slope failures and with significant uncertainty. No information on the time or period of occurrence was available for the sinkholes. We conclude that the ability to obtain accurate temporal information for the different hazards, which is important for establishing and validating early warning systems, depended on the extent and the location of the different hazards. The temporal information was most accurate for flooding along the Cande- 
laro River (Fig. 3h), followed by flash floods and landslides (Fig. 3), and was not available for the sinkholes.

We used the rainfall and the landslide information available to us to design and test the new ensemble-nonexceedance probability (E-NEP) algorithm for the quantitative evaluation of the probability of possible occurrence of rainfall-induced landslides and of related geohydrological hazards (e.g. flash floods, sinkholes). For the investigated rainfall events, the ensemble of the metrics produced by the E-NEP algorithm provided better diagnostics than the single metrics often used for landslide forecasting, including rainfall duration, cumulated rainfall and rainfall intensity (Guzzetti et al., 2007; Brunetti et al., 2010; Peruccacci et al., 2012). We maintain that the E-NEP algorithm is potentially useful for landslide early warning, but we acknowledge that more work is needed to test the algorithm in different meteorological, geological and physiographical settings.

Our analysis revealed that in the Gargano Promontory meteorologically driven hazards occur in response to extreme (i.e. rare) meteorological conditions, and the karst landscape responds to torrential rainfall with a threshold behaviour. For light to heavy rainfall events (Alpert et al., 2002) landslides, floods and sinkholes do not occur or are rare and minor, whereas for heavy-torrential to torrential rainfall events they are abundant and particularly disruptive, as for the case for the 1-6 September 2014 event. We maintain that this information is useful for landslide early warning systems (and for other geohydrological hazards).

Competing interests. The authors declare that they have no conflict of interest.

Acknowledgements. Work performed in the framework of projects supported by the Italian National Department for Civil Protection (DPC), and the Puglia (Apulia) Regional Government (PRG). Maria Elena Martinotti and Massimo Melillo were supported by two grants of DPC. Luca Pisano was supported by a grant of PRG.

Edited by: A. Günther

Reviewed by: J. De Waele and one anonymous referee

\section{References}

Abramowitz, M. and Stegun, I. A. (Eds): Handbook of Mathematical Functions with Formulas, Graphs, and Mathematical Tables, 9th printing, New York, 1972.

Alpert, P., Ben-Gai, T., Baharan, A., Benjamini, Y., Yekutieli, D., Colacino, M., Diodato, L., Ramis, C., Homar, V., Romero, R., Michaelides, S., and Manes, A.: The paradoxical increase of Mediterranean extreme daily rainfall in spite of decrease in total values, Geophy. Res. Lett., 29, 31-1-31-4, doi:10.1029/2001GL013554, 2002.
Bissanti, A. A.: L'alluvione del luglio 1972 a Manfredonia, Mem Ist Geogr Fac Econ Comm Università Bari, 5-73, 1972.

Bosellini, A., Morsilli, M., and Neri, C.: Long-term event stratigraphy of the Apulia platform margin (Upper Jurassic to Eocene; Gargano, southern Italy), J. Sediment. Res., 69, 1241-1252, 1999.

Brankman, C. M. and Aydin, A.: Uplift and contractional deformation along a segmented strike-slip fault system: the Gargano Promontory, southern Italy, J. Struct. Geol., 26, 807-824, 2004.

Brunetti, M. T., Peruccacci, S., Rossi, M., Luciani, S., Valigi, D., and Guzzetti, F.: Rainfall thresholds for the possible occurrence of landslides in Italy, Nat. Hazards Earth Syst. Sci., 10, 447-458, doi:10.5194/nhess-10-447-2010, 2010.

Cannon, S. H., Gartner, J. E., Rupert, M. G., Michael, J. A., Rea, A. H., and Parrett, C.: Predicting the probability and volume of post wildfire debris flows in the intermountain western United States, Geol. Soc. Am. Bull., 122, 127-144, 2010.

Castiglioni, B. and Sauro, U.: Large collapse dolines in Puglia (southern Italy): the cases of "Dolina Pozzatina" in the Gargano plateau and of "puli" in the Murge, Acta Carsologica, 29, 83-93, 2000.

De Graff, J. V., Cannon, S. H., and Parise, M.: Limiting the immediate and subsequent hazards associated with wildfires, in: Landslide science and practice, volume 4, Global Environmental Change, Springer, 199-209, 2013.

De Waele, J., Gutiérrez, F., Parise, M., and Plan, L.: Geomorphology and natural hazards in karst areas: A review, Geomorphology, 134, 1-8, 2011.

Fleury, P., Maréchal, J. C., and Ladouche, B.: Karst flash-flood forecasting in the city of Nîmes (southern France), Eng. Geol., 164 26-35, doi:10.1016/j.enggeo.2013.06.007, 2013.

Ford, D. C. and Williams, P.: Karst Hydrogeology and Geomorphology, Wiley, Chichester, 562 pp., 2007.

Funiciello, R., Montone, P., Salvini, F., and Tozzi, M.: Caratteri strutturali del promontorio del Gargano, Mem. Soc. Geol. It., 41, 1235-1243, 1988.

Gutiérrez, F., Guerrero, J., and Lucha, P.: A genetic classification of sinkholes illustrated from evaporite paleokarst exposures in Spain, Environ. Geol., 53, 993-1006, 2008.

Gutiérrez, F., Parise, M., De Waele, J., and Jourde, H.: A review on natural and human-induced geohazards and impacts in karst, Earth-Sci. Rev., 138, 61-88, 2014.

Guzzetti, F., Peruccacci, S., Rossi, M., and Stark, C. P.: Rainfall thresholds for the initiation of landslides in central and southern Europe, Meteorol. Atmos. Phys., 98, 239-267, doi:10.1007/s00703-007-0262-7, 2007.

Moody, J. A., Shakesby, R. A., Robichaud, P. R., Cannon, S. H., and Martin, D. A.: Current research issues related to postwildfire runoff and erosion processes, Earth-Sci. Rev., 122, 10 37, doi:10.1016/j.earscirev.2013.03.004, 2013.

Mossa, M.: The floods in Bari: what history should have taught, J. Hydraul. Res., 45, 579-594, 2007.

Parise, M.: Flood history in the karst environment of CastellanaGrotte (Apulia, southern Italy), Nat. Hazards Earth Syst. Sci., 3, 593-604, doi:10.5194/nhess-3-593-2003, 2003.

Parise, M. and Gunn, J. (Eds.): Natural and anthropogenic hazards in karst areas: Recognition, Analysis and Mitigation, Geological Society, Special Publication 279, London, 2007. 
Parise, M., Ravbar, N., Živanovic, V., Mikszewski, A., Kresic, N., Mádl-Szonyi, J., and Kukuric, N.: Hazards in Karst and Managing Water Resources Quality, in: Karst Aquifers - Characterization and Engineering, Professional Practice in Earth Sciences, edited by: Stevanovic, Z., Springer, 601-687, doi:10.1007/9783-319-12850-4_17, 2015.

Peruccacci, S., Brunetti, M. T., Luciani, S., Vennari, C., and Guzzetti, F.: Lithological and seasonal control on rainfall thresholds for the possible initiation of landslides in central Italy, Geomorphology, 139-140, 79-90, 2012.

Polemio, M. and Lonigro, T.: Variabilità climatica e ricorrenza delle calamità idrogeologiche in Puglia, in: Le modificazioni climatiche e i rischi naturali, edited by: Polemio, M., CNR IRPI, Bari, 13-16, 2011.
Shepard, D.: A two-dimensional interpolation function for irregularly-spaced data, in: Proceedings of the 1968 23rd ACM national conference, ACM, New York, 517-524, 1968.

Simone, O. and Fiore, A.: Five Large Collapse Dolines in Apulia (Southern Italy) - the Dolina Pozzatina and the Murgian Puli, Geoheritage, 6, 291-303, 2014.

Williams, P. W.: The role of the epikarst in karst and cave hydrogeology: a review, Int. J. Speleol., 37, 1-10, 2008. 